\title{
PAUL PEARSON
}

Forey seeks to establish the uncompromising view that the stratigraphic record is "of no use in reconstructing phylogenies", but in doing so he argues against his own caricature of the stratophenetic method. Here I wish to make clear exactly what I am(and am not) claiming can be accomplished through stratophenetics.

I did not argue that stratigraphic evidence is paramount "at any taxonomic level". In fact, the stratophenetic method is restricted to investigating relationships within and between species. I also tried to stress that stratophenetics should not be seen as a replacement for cladistics, and that its applicability is strictly limited to the very best parts of the fossil record.

\section{Forey's thought experiment}

Forey asks us to consider five species of sea urchin (A-E) in successive stratigraphic horizons. The question is: How do we set about establishing relationships among them?

Although we cannot rule out a possible lineage (direct line of descent) from A to $\mathrm{B}$ to $\mathrm{C}$ to $\mathrm{D}$ to $\mathrm{E}$, it is not remotely parsimonious because it requires a reversal in the one character we are given. There is no way that I or any sane palaeontologist would argue for stratophenetic linkage between them on the evidence presented!

Forey goes on to suggest that further data might help in our deliberations and he proposes cladistic analyses of morphological or molecular data. I agree that this could be very informative. Indeed, it is the optimal approach for the vast majority of practical palaeontological problems.

\section{Back to the rock face}

I have agreed with Forey that cladistics is the optimal approach for most palaeontological problems of phylogeny. It is not, however, the only conceiveable approach. Since Forey allowed himself to introduce additional evidence into his scenario, I will do the same.

Imagine that the type of species in question in our thought experiment is very abundant and widespread, and that the preservation of individuals is routine. Then imagine that we are able to demonstrate (by orbital chronology for example) that the sediment succession in which the fossils are found is continuous. We can sample the succession at will, and increase our data set from five to perhaps fifty or a hundred closely spaced stratigraphically ordered samples. Each sample consists of thousands of individuals, although perhaps we only have the resources to make measurements on say a hundred at a time. Finally, we can, if we choose, repeat the exercise at a number of other sites around the world to double-check for unseen gaps and intervals of condensation, etc.

Such a study might reveal all sorts of patterns of evolution in the clade that comprises species A to E. Let us imagine, however, that each stratigraphic horizon contains a unimodal population in which the range of variation is similar to that seen in modern species of the same type. We also find that our five original "species" are no longer as "distinct" as they first appeared, but rather shade into one another through complete intergradation. Each of our samples has substantial phenetic overlap in all characters with its predecessor and successor.

At this stage we have a choice. We can either a) throw away the tags that tell us the stratigraphic levels of our samples and attempt a cladistic analysis, or b) admit the utility of the stratigraphic evidence and proceed with a hypothesis of 
stratophenetic linking.

A cladistic analysis would present us with formidable problems, though. How do we decide which of our thousands of measured specimens is a potential "Operational Taxonomic Unit" (OTU)? If we refrain from using them all (which would produce an absurd result even if it was practicable), we must start by making some sort of plausibility argument that individuals with similar morphologies belong in species. In other words, we must at least start off down the road of phenetic linking.

Some cladists might respond to this by remarking that we have now established through additional collecting that there is only one OTU involved (not five as originally thought), and that, therefore, a phylogenetic analysis is superfluous. Fine, but what if the record happened to show a case in which we started off with one population in a sample and ended up with two distinct coexisting populations that sprout from it?

Of course, no matter how many data we collect we will never be able to prove a hypothesis of ancestry beyond any doubt. Fortunately, science rarely, if ever, requires hypotheses to be proven absolutely before they can be usefully applied.

\section{Stratophenetics in the microfossil record}

In his email, McLeod deals with practical rather than theoretical objections to stratophenetics, but he also attributes views to me that I do not hold. I am entirely in agreement with him over the general poor quality of the marine sediment record. It is indeed full of gaps and hiatuses of all durations, and biostratigraphical datums are often quite diachronous ${ }^{1}$. Some time intervals are subject to very widespread hiatuses in the oceans. Much of the ocean floor is covered by turbidites. So what?

The point is that there are places in the oceans where such problems are greatly reduced. Thanks to an intelligent coring program (pioneered by geochemists) we have now recovered many sites with long intervals of effective continuity. We should exploit these opportunities as they arise and push for more to be drilled.

There is broad agreement of the (entirely non-cladistic) palaeontological phylogenies with the genetic data of Pawlowski \& de Vargas and others. This is "encouraging", although I do not suggest that it represents "a justification for stratophenetics". It is early days in the sequencing of planktonic foraminifera, and data from only one ribosomal gene has so far been published. I look forward to the near future envisaged by Hedges when much more genetic information will be available.

Finally, McLeod seems to think that disagreement between workers over evolutionary relationships is a bad sign. If only cladistic phylogenies were always so perfect that no further debate was necessary! Of course, new data (genetic and morphological) will continually require us to make changes to our phylogenies. It is because we care about their accuracy that we gather new data in the first place.

Paul N. Pearson

Department of Earth Sciences, University of Bristol, Bristol, UK

\section{References}

1. Pearson, P.N. Evolutionary concepts in biostratigraphy. in Unlocking the Stratigraphical Record. (Doyle, P. \& Bennett, M.R. eds)123-144 (John Wiley \& Sons. New York, 1998). 